\title{
A comparative study of maternal and fetal outcomes following induction of labour versus expectant management in mild gestational hypertension at term
}

\author{
Anjuman Alam*, Poonam Choubey
}

Department of Obstetrics and Gynecology, Assam Medical College and Hospital, Dibrugarh, Assam, India

\author{
Received: 02 February 2019 \\ Accepted: 06 March 2019

\section{*Correspondence:} \\ Dr. Anjuman Alam, \\ E-mail: dr.anjuman.alam@gmail.com
}

Copyright: () the author(s), publisher and licensee Medip Academy. This is an open-access article distributed under the terms of the Creative Commons Attribution Non-Commercial License, which permits unrestricted non-commercial use, distribution, and reproduction in any medium, provided the original work is properly cited.

\begin{abstract}
Background: To compare the maternal and neonatal outcomes between planned induction of labour and expectant management in women with mild gestational hypertension at term.

Methods: A prospective hospital based observational study. The 120 pregnant women with mild gestational hypertension were randomized in a 1:1 ratio either to receive immediate induction of labour (group A comprising 60 women) or expectant management (group B comprising 60 women). Primary outcomes were incidence of any maternal mortality, renal failure, pulmonary oedema, need for ICU care or post-partum eclampsia and also composite maternal morbidity like severe gestational hypertension, pre-eclampsia, eclampsia, abruption and PPH. Secondary outcomes were mode of delivery, need for antihypertensives and $\mathrm{MgSO}_{4}$.

Results: Though there were no maternal death or renal or pulmonary complications in any group, progression to severe hypertension was more in group B (expectant management) compared to group A (immediate induction) (18.33\% vs. 3.33\%). Increased incidence of pre-eclampsia and eclampsia were noted in group B (15\% and 3\%) as compared to group A (0\%). Incidence of Abruption and PPH was less in group A $1.67 \%$ and 5\% compared to group B $3.33 \%$ and $10 \%$ respectively. Spontaneous vaginal delivery rate was low and caesarean section rates were high in group A (61.67\% and 31.67\%) compared to group B (68.33\% and 25\% respectively). Need for antihypertensive and $\mathrm{MgSO}_{4}$ were less in group A (3.33\% each) compared to group B (18.33\% and $16.66 \%$ respectively).

Conclusions: Requirement of antihypertensive, progression to severe hypertension, pre-eclampsia, eclampsia, use of $\mathrm{MgSO}_{4}$, incidence of abruption, $\mathrm{PPH}$ were less in group A compared to group B. However, induction at completion of 37 weeks may be associated with increased incidence of operative deliveries.
\end{abstract}

Keywords: Expectant management, Induction of labour, Mild gestational hypertension

\section{INTRODUCTION}

Having a baby is a joyous and fulfilling experience for women. Unfortunately, pregnancy and delivery can also cause a stressful life event when the mother's or baby's health is adversely affected, especially in the presence of hypertensive disorders of pregnancy. Hypertensive disorders of pregnancy are one of the leading causes of maternal mortality and severe maternal morbidity, affecting about $10 \%$ of all pregnancies worldwide and pre-eclampsia affects $3.5 \%$ of pregnancies. ${ }^{1,2}$ In India, the incidence of PIH is more than 4 percent $(41.2$ per 1,000$)$ reported in 2009. This level has risen more than 50 percent since 1990 when it was $2 \%$ (27.2 per 1000). ${ }^{3}$

Hypertensive diseases if not controlled at the initial stage can lead to complication in both mother and neonates. In mother it can lead to eclampsia, HELLP syndrome, 
placental abruption, renal failure; thus increasing maternal morbidity and mortality. The risk caused by gestational hypertension to the fetus includes severe growth retardation, hypoxemia, acidosis, premature birth and death. ${ }^{4}$

The management of severe gestational hypertension and preeclampsia at term is clear and the only definitive treatment is delivery. ${ }^{5}$ But the management of mild gestational hypertension at term is not clear. For many years the optimal time for delivery of such women has been controversial. Some guidelines recommended labour induction at 37-38 weeks of gestation whereas other endorse expectant management until development of either a maternal or fetal indication for delivery. ${ }^{6}$ Those who advise delivery at 37-38 weeks of gestation refer to maternal risks of expectant management whereas those who recommend expectant management cite the increased rates of caesarean delivery from induction, particularly in those with unfavorable cervix, as well as the increased rates of neonatal morbidities in infants born at $37+0$ to $38+6$ weeks of gestation. ${ }^{4}$

With the lack of good clinical evidence on the subject and resulting practice variation, additional data comparing immediate delivery and expectant monitoring in patients with hypertensive diseases are needed.

\section{Aims}

- To compare the maternal and neonatal outcomes between planned induction of labour and expectant management in women with mild gestational hypertension at term.

- To study whether there is increase incidence of operative deliveries with induction of labour.

\section{METHODS}

Authors conducted a clinical study in the Department of Obstetrics and Gynecology, Assam Medical College and Hospital, Dibrugarh for a period of one year from $1^{\text {st }}$ July 2016 to $30^{\text {th }}$ June 2017 to compare maternal and fetal outcomes following induction of labour versus expectant management in mild gestational hypertension at term.

The study was a Prospective Hospital Based Observational Study which included 120 patients with mild gestational hypertension attending the Antenatal Out Patient Department or directly attending Labour Room in Assam Medical College and Hospital, Dibrugarh.

The cases were selected as per inclusion and exclusion criteria.

\section{Inclusion criteria}

- Patient 18 years or older with mild gestational hypertension,

- Gestational age 37 completed weeks to 40 weeks,
- $\quad$ Systolic blood pressure 140-159 $\mathrm{mmHg}$ and diastolic blood pressure $90-100 \mathrm{mmHg}$ at 2 occasions at least 6 hours apart,

- Women with singleton pregnancy with vertex presentations,

- All biochemical parameter within normal limit.

\section{Exclusion criteria for cases and controls}

- Severe gestational hypertension, pre-eclampsia, eclampsia, women with diastolic blood pressure $>100 \mathrm{mmHg}$, HELLP syndrome

- Diabetes mellitus, renal disease, heart disease, HIV positive cases,

- Previous LSCS, oligohydramnios, fetal disorder, abnormalities in fetal heart rate or any other medical disorder.

The study consisted of 60 patients in induction group and 60 patients in expectant management group. Eligible patients presenting to the obstetric outpatient department (OPD) or labour room of Assam Medical College were randomized in a 1.1 ratio to receive immediate induction of labour (group A) or expectant management (group B) after taking informed consent. Laboratory examination which includes liver function test, kidney function test, routine urine examination, serum uric acid and blood picture including platelet count were done and any deviation from normal values were excluded from the study.

For those in the immediate induction group, a vaginal examination was done to assess the Bishop's score. If score was 6 or more, artificial rupture of membrane with or without oxytocin augmentation was done within 12 hours of randomization. If the score was less than 6 , cervical ripening was done with PGE2 gel.

The demographic details, details of delivery, drug used, intrapartum and postnatal complications for the mother and baby were noted in a proforma especially made for the study. All events of labour were recorded in a modified WHO partograph.

For those allocated in expectant management group were advised daily home blood pressure (BP) monitoring by a local doctor or nurse. Biweekly visit to the outpatient department was advised until they went into spontaneous labour till 39 weeks and 5 days when labour was induced.

If there was progression of the disease by way of increase in diastolic BP to more than $100 \mathrm{~mm} \mathrm{Hg}$, or proteinuria became more than or equal to $1+$ by heat coagulation method or if the patient developed signs and symptoms of impending eclampsia, suspected fetal distress, eclampsia or HELLP syndrome, labour was induced according to the protocol for induction of labour of this department.

All warning signs of preeclampsia and eclampsia were explained to the patient. 


\section{Statistical analysis}

Data was presented in terms of mean \pm standard deviation and ranges of various parameters were computed. Statistical analysis was performed by using simple linear regression. Chi square test was used for test of categorical variables. Student $t$ test was used for test of maternal morbidity and comparison of continuous variables. A p value $<0.05$ was considered to be statistically significant.

\section{RESULTS}

In the present study, 120 women with mild gestational hypertension were taken out of which 60 patients with mild gestational hypertension were given induction
(Group A) and 60 patients were given expectant management (Group B). The baseline characteristics like maternal age, level of education, locality, gestational age at randomization, average systolic and diastolic blood pressure were comparable in both groups (Table 1 and Figure 1).

The mean maternal age in Group A was $24.47 \pm 2.98$ and that in Group B was 24.27 \pm 2.83 .The maximum number of patients were between 18-24 years in both the groups. Both primigravida and multigravida were affected by gestational hypertension, with a higher incidence in primigravida. There were 39 primigravida patients in group A and 42 in group B. Maximum number of patients were unbooked and were from rural community.

Table 1: Baseline Characteristics.

\begin{tabular}{|c|c|c|c|c|c|}
\hline \multirow{2}{*}{ Variables } & \multicolumn{2}{|c|}{ Group A $(n=60)$} & \multicolumn{2}{|c|}{ Group B $(n=60)$} & \multirow[b]{2}{*}{$\mathrm{p}$ value } \\
\hline & $\mathbf{n}$ & $\%$ & $\mathbf{n}$ & $\%$ & \\
\hline \multicolumn{5}{|l|}{ Age Group (in years) } & \\
\hline $18-24$ & 33 & 55.00 & 30 & 50.00 & \\
\hline $25-30$ & 26 & 43.33 & 28 & 46.66 & \\
\hline$>30$ & 1 & 01.66 & 2 & 03.33 & \\
\hline Mean \pm SD & \multicolumn{2}{|c|}{$24.47 \pm 2.98$} & \multicolumn{2}{|c|}{$24.27 \pm 2.83$} & 0.7069 \\
\hline \multicolumn{6}{|l|}{ Parity } \\
\hline Primigravida & 39 & 65 & 42 & 70 & \multirow{2}{*}{0.5587} \\
\hline Multigravida & 21 & 35 & 18 & 30 & \\
\hline \multicolumn{6}{|l|}{ Booking Status } \\
\hline Booked & 19 & 31.67 & 18 & 30 & \multirow{2}{*}{0.8434} \\
\hline Unbooked & 41 & 68.33 & 42 & 70 & \\
\hline \multicolumn{6}{|l|}{ Locality } \\
\hline Rural & 40 & 66.67 & 46 & 76.67 & \multirow{2}{*}{0.2242} \\
\hline Urban & 20 & 33.33 & 14 & 23.33 & \\
\hline \multicolumn{6}{|l|}{ Socioeconomic Status } \\
\hline Upper Class & 0 & 0 & 0 & 0 & - \\
\hline Upper Middle & 0 & 0 & 0 & 0 & - \\
\hline Lower Middle & 11 & 18.33 & 7 & 11.67 & 0.3064 \\
\hline Upper Lower & 42 & 70.00 & 43 & 71.67 & 0.8414 \\
\hline Lower & 7 & 11.67 & 10 & 16.67 & 0.4321 \\
\hline \multicolumn{6}{|l|}{ Gestational Age (in weeks) } \\
\hline 37 completed weeks & 24 & 40.00 & 35 & 58.33 & 0.0445 \\
\hline 37.1-38 completed weeks & 25 & 41.67 & 21 & 35.00 & 0.4526 \\
\hline 38.1-39 completed weeks & 11 & 18.33 & 4 & 6.67 & 0.5336 \\
\hline 39.1-40 completed weeks & 0 & 0.00 & 0 & 0.00 & - \\
\hline
\end{tabular}

Table 2: Distribution of patients according to the primary outcome.

\begin{tabular}{|c|c|c|c|c|c|}
\hline \multirow{2}{*}{ Outcome } & \multicolumn{2}{|c|}{ Group A $(n=60)$} & \multicolumn{2}{|c|}{ Group B $(n=60)$} & \multirow{2}{*}{$p$ value } \\
\hline & n & $\%$ & n & $\%$ & \\
\hline Progression to severe hypertension & 2 & 3.33 & 11 & 18.33 & 0.0188 \\
\hline Pre-eclampsia & 0 & 0 & 9 & 15 & 0.0056 \\
\hline Eclampsia & 0 & 0 & 3 & 5 & 0.2422 \\
\hline Abruption & 1 & 1.67 & 2 & 3.33 & 1.0000 \\
\hline PPH & 3 & 5 & 6 & 10 & 0.4882 \\
\hline
\end{tabular}


Table 3: Secondary outcomes of the mother.

\begin{tabular}{|c|c|c|c|c|c|}
\hline \multirow{2}{*}{ Outcomes } & \multicolumn{2}{|c|}{ Group A $(n=60)$} & \multicolumn{2}{|c|}{ Group B (n = 60) } & \multirow[b]{2}{*}{ p value } \\
\hline & n & $\%$ & n & $\%$ & \\
\hline \multicolumn{6}{|l|}{ Mode of delivery } \\
\hline SVD & 37 & 61.67 & 41 & 68.33 & 0.5659 \\
\hline ID & 4 & 6.67 & 4 & 6.67 & 1.0000 \\
\hline $\mathrm{CS}$ & 19 & 31.67 & 15 & 25 & 0.5434 \\
\hline Need for antihypertensive & 2 & 3.33 & 11 & 18.33 & 0.0188 \\
\hline Need for $\mathrm{MgSO}_{4}$ & 2 & 3.33 & 10 & 16.66 & 0.0332 \\
\hline
\end{tabular}

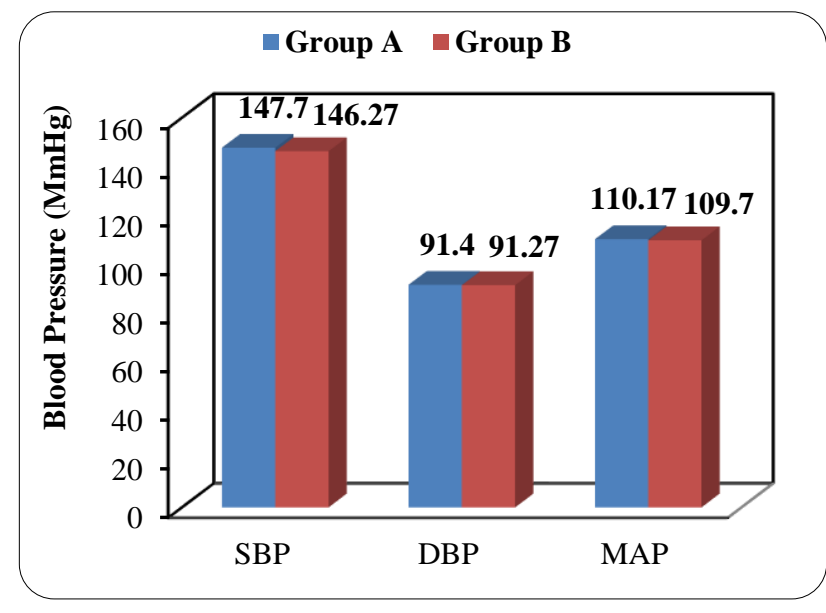

Figure 1: Distribution of cases according to their blood pressure.

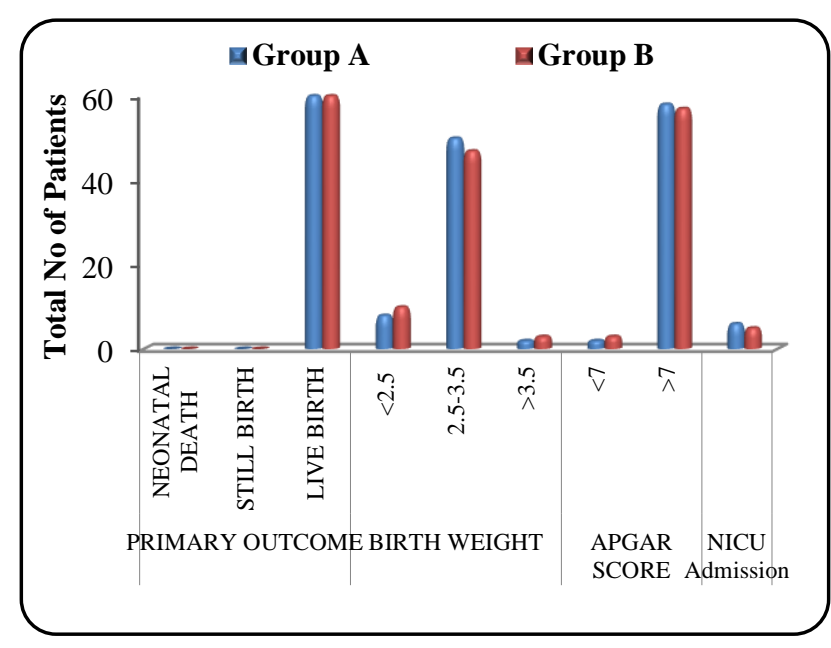

Figure 2: Distribution of neonates according to outcomes.

The gestational age in the induction group (Group A) were in between 37.1-38 completed weeks in majority of the patients and that of expectant management group was 37 completed weeks.

Mean systolic pressure in Group A was 147.70 \pm 5.67 and that in group B was $146.57 \pm 5.38$. Similarly mean diastolic pressure in group A was $91.40 \pm 1.96$ and that in Group B was $91.27 \pm 2.33$. The mean arterial pressure in group A was 110.17 \pm 2.71 and that in Group B was $109.70 \pm 2.34$ as shown in Figure 1. The intergroup differences were comparable and not statistically significant.

Regarding the primary outcomes, there were no cases of maternal mortality, renal failure, pulmonary oedema, need for ICU care or post partum eclampsia in either groups. However, there was increased incidence of composite maternal morbidity (severe gestational hypertension, pre-eclampsia, eclampsia, abruption and $\mathrm{PPH}$ ) in expectant group when compared to the induction group.

In the expectant management group, eleven patients progressed to severe hypertension as compared to only two patients in induction group which was significant statistically. Nine patients developed preeclampsia in expectant group whereas no patients in induction group developed pre-eclampsia which was also significant statistically. Three patients progressed to eclampsia in expectant group whereas none from induction group developed eclampsia. One patients from induction group developed abruption as compared to two patients from expectant group, which was not significant statistically. Three patients had PPH in induction group as compared to six patients in expectant management group (Table 2).

Considering secondary outcome of the mother, there were more patients with spontaneous onset of labour in the expectant management group as compared to induction group. It was seen that number of patients requiring caesarean sections were increased in group $A$ as compared to group B although not significant. Number of instrumental deliveries however remained the same in both the groups. But the number of patients requiring antihypertensives and magnesium sulphate $\left(\mathrm{MgSO}_{4}\right)$ were increased in expectant management group which were significant (Table 3).

It was seen that in present study there was no neonatal death and still birth in either group. There was no statistically significant difference in the neonatal morbidity between the two groups. A slight increase in NICU admission was seen in induction group. There were more babies with low birth weight in Group A as compared to Group B which was not significant 
statistically. The Apgar score was $\leq 7$ in $2(3.33 \%)$ babies in Group A and 3 (5\%) babies in Group B which was not statistically significant (Figure 2).

\section{DISCUSSION}

Preeclampsia leads to increased perinatal morbidity and the primary objective of management in women with gestational hypertension is to prevent complications to the mother and the foetus and subsequent delivery of a healthy baby.

In the present study, when the baseline characteristics were compared it was seen that the mean age and parity were similar in both Group A and Group B which was similar to the study conducted by Pallipuram et al and Khaskheli MN et al, and also HYPITAT trial. ${ }^{4,7,8}$ In the present study gestational hypertension was seen more in unbooked cases $(68.33 \%$ in group $\mathrm{A}$ and $70 \%$ in group B). Bangal VB et al, also found that $80 \%$ of the patients were unbooked. ${ }^{9}$ Majority of the patients in the present study were from rural community $(66.67 \%$ in group $\mathrm{A}$ and $76.67 \%$ in group B) and studied only till primary school (40\% in group A and $38.33 \%$ in group B). The mean systolic pressure and diastolic pressure in both groups in the present study were comparable which was similar to the study conducted by Pallipuram et al. ${ }^{4}$

It was seen that in the present study, $30 \%$ patients from Group B underwent spontaneous onset of labor whereas none (0) from group A underwent spontaneous onset of labor which was significant statistically. The HYPITAT Trial8 showed that $53 \%$ patients in expectant group underwent spontaneous onset of labour as compared to $3 \%$ patients in induction group.

When the primary outcomes of the mother was compared, it was seen that progression to severe hypertension was seen in more in Group B then in Group A (18.33\% versus $3.33 \%$ respectively) and the difference was significant statistically. It was similar to the study of Pallipuram et al, and The HYPITAT trial which also reported increased progression to severe hypertension in conservative group in comparison to the induction group. ${ }^{4,8}$ Similarly progression to preeclampsia and eclampsia was more in conservative management group as compared to induction group which was also seen in study conducted by Pallipuram et al. ${ }^{4}$

The present study found increased incidence of PPH in the conservative group in comparison to the induction group which was similar to the study conducted by Pallipuram et al 4 and The HYPITAT trial. ${ }^{8}$ They found no incidence of abruption in either group, whereas in the present study Group B had slightly increased incidence of abruption cases compared to Group A (3.33\% vs. 1\%) although the differences were not significant statistically.

In the present study, there were no incidence of pulmonary oedema, renal failure and need for ICU care in either group similar to the study conducted by Pallipuram et al, whereas the HYPITAT trial reported development of pulmonary oedema in $1 \%$ patients in the expectant group and none in induction group and two percent patients in the induction group needed ICU care in comparison to $4 \%$ in the expectant group; none from either group reported an incidence of renal failure in their trial. $^{4,8}$

When the secondary outcomes of the mother was compared, in the present study, there were no statistically significant differences in the instrumental delivery and caesarean section rates between the two groups ( $\mathrm{p} 1.0000$ and 0.5434 respectively) although Group $\mathrm{A}$ had an increase number of caesarean sections as compared to group B similar to the study conducted by Pallipuram et al. ${ }^{4}$ The HYPITAT trial reported increased number of caesarean sections and instrumental deliveries in the expectant group although no statistical differences in the rates of instrumental delivery and caesarean section rates ( $p=0.93$ vs 0.75 ) were found. ${ }^{8}$ In the present study, it was seen that patients in Group B (expectant group) required more use of antihypertensive drugs and intrapartum magnesium sulphate for seizure prophylaxis compared to Group A (induction group) which was significant statistically $(\mathrm{p}=0.0188$ and 0.0332 respectively) similar to the study of conducted by Pallipuram et al, and HYPITAT trial. ${ }^{4,8}$

Regarding neonatal outcomes, there were no neonatal deaths in either group which was similar to HYPITAT trial. Whereas the study conducted by Pallipuram et al, reported 1 neonatal death in the induction group and no neonatal death in the conservative group although the differences were not significant statistically in both the studies. ${ }^{4}$

The present study recorded a slightly increased number of low birth weight babies in Group A (induction group) compared to Group B (expectant group) which was similar to the study conducted by Pallipuram et al. ${ }^{4}$ The HYPITAT trial 8 had only $1 \%$ infants with low birth weight in induction arm and none in expectant management arm to required NICU admissions.

Neonates with APGAR score $<=7$ was more in conservative group as compared to induction group but the differences were not significant statistically. These findings were similar to the study conducted by Pallipuram et al, who had only $2 \%$ neonates with Apgar score $<=7$ in both groups. ${ }^{4}$ The HYPITAT trial had also only $2 \%$ infants in both groups with Apgar score $<=7 .^{8}$

The study conducted by Pallipuram et al, found increased rates of admission to NICU in the induction group compared to the conservative management group which was similar to present study. In the present study NICU admission was more in induction group. ${ }^{4}$ The HYPITAT trial also reported increase number of NICU admissions in the induction group compared to the expectant group. 


\section{CONCLUSION}

The complications associated with hypertensive disorders of pregnancy depends on the severity of disease process, gestational age at onset, fetal and maternal conditions at the time of diagnosis and timing of delivery. It was seen that induction of labour at term followed by delivery helped in reducing progression to severe hypertension, development of preeclampsia and eclampsia and use of magnesium sulphate intrapartum and postpartum in the mother in comparison to expectant management. There were also decrease requirements of antihypertensive intake in induction group along with decrease number of abruption and postpartum hemorrhage cases in the induction group. However, induction at completion of 37 weeks may be associated with increased incidence of operative deliveries.

Maternal and perinatal mortalities and morbidities can be reduced to a greater extent if planned delivery is done at term. Further large scale, multicentric study will help in determining the limitations of induction and expectant management in mild gestational hypertension at term..

\section{ACKNOWLEDGMENTS}

Authors would like to thank the Department of Obstetrics and Gynaecology, Assam Medical College and Hospital, Dibrugarh.

\section{Funding: No funding sources}

Conflict of interest: None declared

Ethical approval: The study was approved by the Institutional Ethics Committee

\section{REFERENCES}

1. Duley L. The global impact of pre-eclampsia and eclampsia. Seminars in Perinatology. 2009;33:130-7.

2. Steegers EA, von Dadelszen P, Duvekot JJ, Pijnenborg R. Pre-eclampsia. Lancet. 2010;376(9741):631-44.
3. Martin JA, Hamilton BE, Ventura SJ, Osterman MJ, Kirmeyer S, Mathews TJ, et al. Births: final data for 2009. National vital statistics reports: from the Centers for Disease Control and Prevention, National Center for Health Statistics, National Vital Statistics System. 2011;60(1):1-70.

4. Bhageerathy PS, Thomas V, Regi A, Jose R. Induction of labour versus conservative management for mild gestational hypertension at term. International Journal of Reproduction, Contraception, Obstet Gynecol. 2017;5(3):689-95.

5. Ganzevoort W, Sibai BM. Temporising versus interventionist management (preterm and at term). Best Pract Resea Clini Obstet Gynaecol. 2011;25(4):463-76.

6. Sibai BM. Management of late preterm and earlyterm pregnancies complicated by mild gestational hypertension/pre-eclampsia. In Seminars in Perinatology. 2011;35(5):292-6.

7. Khaskheli MN, Baloch S, Sheeba A, Baloch S, Khan F. Labour induction with Gestational Hypertension: A great obstetric challenge. Pak J Medi Scien. 2017;33(1):151.

8. Koopmans CM, Bijlenga D, Groen H, Vijgen SM, Aarnoudse JG, Bekedam DJ, van den Berg PP, et al. Induction of labour versus expectant monitoring for gestational hypertension or mild pre-eclampsia after 36 weeks' gestation (HYPITAT): a multicentre, open-label randomised controlled trial. The Lancet. 2009;374(9694):979-88.

9. Bangal VB, Giri PA, Mahajan AS. Maternal and fetal outcome in pregnancy induced hypertension: A study from rural Tertiary care teaching hospital in India. Int J Biomed Resea. 2011;2(12):595-9.

Cite this article as: Alam A, Choubey P. A comparative study of maternal and fetal outcomes following induction of labour versus expectant management in mild gestational hypertension at term. Int J Reprod Contracept Obstet Gynecol 2019;8:1889-94. 